\title{
Toxicidade do Herbicida S-Metolachlor em Plantas de Milho Provenientes de Sementes com Diferentes Formatos e Dimensões ${ }^{1}$
}

\author{
S-Metholachlor Toxicity in Maize Plants Originated From Seeds with Different Sizes and Shapes
}

\author{
ROSENTHAL, M.D.A. ${ }^{2}$, PROCÓPIO, S.O. ${ }^{3}$, PINTO, J.J.O. ${ }^{4}$, JACOB JÚNIOR, E.A. ${ }^{5}$, PERES, \\ W.B. ${ }^{6}$, MANICA, R. ${ }^{7}$, ZANATTA, J.F. ${ }^{8}$, CARGNELUTTI FILHO, A. ${ }^{9}$, SGANZERLA, D.C. ${ }^{7}$, \\ CARNEIRO, J.C. ${ }^{7}$, CANABARRO, L.G. ${ }^{7}$ e FRANZINI, W. ${ }^{10}$
}

\begin{abstract}
RESUMO - Este trabalho teve como objetivo avaliar a toxicidade do herbicida S-metolachlor em plantas de milho oriundas de sementes com diferentes características morfológicas. $\mathrm{O}$ experimento foi conduzido em casa de vegetação, localizada no município de Capão do Leão, RS. Os tratamentos foram compostos pelas combinações de três grupos de tamanhos de sementes, classificadas em peneiras de crivo oblongo [sementes retidas nas peneiras de largura 14/64" (peneira 14), 18/64" (peneira 18) e 21/64" (peneira 21)], de dois formatos de sementes (chata e redonda) e de cinco doses do herbicida S-metolachlor $(0,00 ; 0,48 ; 0,96 ; 1,44$; e $1,92 \mathrm{~kg} \mathrm{ha}^{-1}$ ), totalizando-se 30 tratamentos. O delineamento experimental utilizado foi o de blocos casualizados em esquema fatorial ( $3 \times 2 \times 5)$, com quatro repetições. Após a separação e classificação das sementes, procedeu-se à semeadura em vasos preenchidos com solo homogeneizado. Em cada vaso foram semeadas oito sementes de milho, na profundidade de $3,0 \mathrm{~cm}$, realizando-se, 24 horas depois, a aplicação do S-metolachlor em pré-emergência. Foram realizadas as seguintes avaliações: velocidade de emergência das plântulas; número total de plântulas emergidas; toxicidade visual e altura de plantas aos 7, 14 e 21 dias após a emergência (DAE); e biomassa seca das raízes e da parte aérea aos 21 DAE. O formato das sementes se mostrou fator importante na tolerância das plantas aos efeitos tóxicos do herbicida S-metolachlor, aplicado em pré-emergência, quando as sementes de milho são de menor tamanho, sendo observada maior toxicidade quando as plantas eram provenientes de sementes redondas. O aumento das doses aplicadas do S-metolachlor ocasionou reduções na aquisição de biomassa seca tanto da parte aérea como das raízes de plantas de milho, porém maior decréscimo se observou quanto ao acúmulo de biomassa seca das raízes.
\end{abstract}

Palavras-chave: Zea mays, pré-emergência, acetamidas.

\begin{abstract}
This experiment aimed to evaluate the toxicity of the herbicide S-metolachlor in corn plants originated from seeds with different morphological characteristics. It was conducted under greenhouse conditions, in the municipal district of Capão do Leão, RS. The treatments consisted of combinations of three groups of seed size classified in an oblong sieve [seeds retained in sieve width of 14/64 "(sieve 14), 18/64 "sieve (sieve 18) and 21/64" sieve (sieve 21 ), in two seed formats (crushed and round) and five doses of the herbicide S-metolachlor $\left(0.00 ; 0.48 ; 0.96 ; 1.44\right.$; and $\left.1.92 \mathrm{~kg} \mathrm{ha}^{-1}\right)$, in 30 treatments. The experiment was arranged in a randomized block design in a factorial scheme ( $3 \times 2 \times 5)$, with four repetitions. After being separated and classified, the seeds were sown in vases filled with homogenized soil. In each vase eight corn seeds were sown at a depth of $3.0 \mathrm{~cm}, 24$ hours after the application of
\end{abstract}

\footnotetext{
Recebido para publicação em 18.10.2005 e na forma revisada em 5.5.2006.

2 Engenheiro-Agrônomo, Dep. Fitossanidade, Universidade Federal de Pelotas - UFPel, 96010-900 Pelotas-RS, <marianer@ufpel.tche.br>. ${ }^{3}$ Professor, Faculdade de Agronomia, Fesurv - Universidade de Rio Verde, 75901-970 Rio VerdeGO. ${ }^{4}$ Professor, Dep. Fitossanidade, UFPel; ${ }^{5}$ Mestrando em Ciência e Tecnologia de Sementes, UFPel; ${ }^{6}$ Professor, Dep. Engenharia Agrícola, UFPel; ${ }^{7}$ Acadêmico em Engenharia Agronômica, UFPel $;{ }^{8}$ Mestrando em Fitossanidade, UFPel. ${ }^{9}$ Professor, Dep. Ciências Exatas, UNESP/FCAV, 14884-900 Jaboticabal-SP. ${ }^{10}$ Mestrando em Produção Vegetal, Fesurv - Universidade de Rio Verde.
} 
S-metolachlor in pre-emergence. The following evaluations were performed: seedling emergence speed, total number of emerged seedlings; visual injury and height of seedlings at 7, 14 and 21 days after emergence (DAE); dry biomass of the roots and aerial part at 21 DAE. Seed format was found to be an important factor in plant tolerance to the toxic effects of S-metolachlor, applied in pre-emergence, for smaller corn seeds and greater toxicity when the plants were originated from round seeds. Increased S-metolachlor doses caused reductions in dry biomass acquisition, both in the aerial part and in the roots of the corn plants. However, a greater reduction was observed in dry biomass accumulation of the roots.

Keywords: Zea mays, pre-emergence, acetamides.

\section{INTRODUÇÃO}

No mundo, a cultura que apresenta o maior consumo do herbicida S-metolachlor é o milho. No entanto, problemas de toxicidade desse herbicida em plantas de milho ainda ocorrem em diversas áreas de produção, e trabalhos indicam que sob temperaturas baixas esses problemas podem ser agravados (Viger et al., 1991; Kunkel et al., 1996).

Segundo Boldt \& Barret (1989), a cultura do milho normalmente é tolerante ao metolachlor, mas injúrias na cultura causadas por aplicações em pré-emergência têm sido observadas quando ocorrem temperatura baixa e alta umidade do solo antes da emergência da cultura.

Viger et al. (1991), estudando os efeitos da interação entre níveis de água no solo e temperatura sobre a tolerância do milho ao metolachlor, observaram correlação direta entre o nível de injúria e o aumento na dose do herbicida, porém a toxicidade foi maior nas plantas crescidas em vasos mantidos com maior umidade inicial do substrato e submetidos a temperatura menor. Resultados semelhantes foram observados por Jordan \& Harvey (1978), os quais verificaram que a tolerância de plantas de milho e ervilha ao herbicida alachlor, também pertencente ao grupo das cloroacetamidas, diminuiu com o aumento na umidade do solo e com o decréscimo na temperatura. Para Cottingham \& Hatzios (1992), em campo, lento crescimento de plântulas de milho pode aumentar a sua sensibilidade ao metolachlor, por prolongar o tempo de contato entre o coleóptilo e o solo tratado com o herbicida.
Fuerst \& Gronwald (1986) relatam que, em gramíneas intoxicadas pelo metolachlor, as folhas podem não se desenvolver do coleóptilo e, quando se desenvolvem, freqüentemente não se desenrolam completamente. Em latifoliadas, a emergência é retardada e as folhas podem ficar enrugadas ou em "forma de concha", além da redução no crescimento da parte aérea e de raízes em ambos os grupos de plantas.

A tolerância ao metolachlor pode estar ligada a vários fatores, como: solo, clima, manejo da irrigação, dose do produto, entre outros. Características relacionadas às sementes das culturas, como o tamanho e o formato, também podem influenciar a seletividade de herbicidas aplicados em pré-emergência, mas são pouco estudadas. Andersen (1970) verificou diminuição na biomassa seca da parte aérea de vários cultivares de soja quando as sementes foram semeadas em solo que recebeu aplicações do herbicida atrazine e que essa redução aumentava à medida que o tamanho das sementes dos cultivares diminuía, concluindo que cultivares de soja que apresentam sementes grandes são mais tolerantes ao atrazine. De acordo com Cargill \& Santelmann (1971), trifluralin causou maior nível de injúrias e redução da matéria seca em raízes de plântulas de amendoim originadas de sementes menores, em relação às sementes "médias" e "grandes". Todavia, Procópio et al. (2001) observaram que o S-metolachlor ocasionou maior toxicidade visual em plantas de feijão provenientes de sementes maiores.

Segundo Breaux (1987), os herbicidas do grupo das cloroacetamidas são detoxificados em plantas, por conjugação com a glutationa, e em leguminosas, com a homoglutationa. 
O conjugado formado não é tóxico à planta, e em plantas tolerantes a esses herbicidas a conjugação ocorre rapidamente após a absorção, sendo a meia-vida destes herbicidas nessas plantas de cerca de poucas horas. Dixon \& Stoller (1982) relatam que, além da capacidade de sintese de glutationa, diferenças na absorção e translocação do herbicida metolachlor podem ser importantes fatores na tolerância das culturas a este herbicida.

Este trabalho teve como objetivo avaliar a toxicidade do herbicida S-metolachlor em plantas de milho oriundas de sementes com três diferentes tamanhos e dois diferentes formatos, cultivadas em casa de vegetação.

\section{MATERIAL E MÉTODOS}

O experimento foi conduzido em casa de vegetação, pertencente ao Departamento de Fitossanidade da Universidade Federal de Pelotas, utilizando-se um híbrido simples de milho (X1371D - Pioneer) (Zea mays). Os tratamentos foram compostos pelas combinações de três grupos de tamanhos de sementes, classificadas em peneiras de crivo oblongo [sementes retidas nas peneiras de largura 14/64" (peneira 14), 18/64" (peneira 18) e $21 / 64 "$ (peneira 21)], de dois formatos de sementes (chata e redonda) e de cinco doses do herbicida S-metolachlor $(0,00 ; 0,48 ; 0,96$; 1,44; e $1,92 \mathrm{~kg} \mathrm{ha}^{-1}$ ), totalizando-se 30 tratamentos. O delineamento experimental utilizado foi o de blocos casualizados em esquema fatorial ( $3 \times 2 \times 5)$, com quatro repetições.

Após a separação e classificação das sementes, procedeu-se à semeadura em vasos plásticos com capacidade para $10 \mathrm{~L}$, preenchidos com solo homogeneizado, cujas características física e química encontram-se na Tabela 1.

Em cada vaso foram semeadas oito sementes de milho, na profundidade de $3,0 \mathrm{~cm}$, realizando-se, 24 horas depois, a aplicação do S-metolachlor em pré-emergência, utilizandose um pulverizador de precisão pressurizado com $\mathrm{CO}_{2}$, aplicando-se volume de calda de $150 \mathrm{~L} \mathrm{ha}^{-1}$. Após a semeadura do milho e aplicação do herbicida, manteve-se o substrato em todas as parcelas com mesmo teor de umidade, por meio de pesagens dos recipientes, até a colheita do experimento, realizada aos 21 dias após a emergência (DAE).

Foram realizadas as seguintes avaliações: índice de velocidade de emergência das plântulas, conforme Maguire (1962); fitotoxicidade visual aos 7, 14 e 21 DAE, utilizando-se uma escala percentual, em que $0 \%$ significa nenhuma injúria e 100\% morte das plantas; altura das plantas aos 7, 14 e 21 DAE; e biomassa seca das raízes e da parte aérea aos 21 DAE.

Todas as variáveis que atenderam às pressuposições de normalidade e homogeneidade das variâncias, por meio dos testes de Lilliefors e de Cochran (Ribeiro Júnior, 2001), respectivamente, foram submetidas à análise de variância, para verificação de significância dos três fatores estudados e da interação entre eles pelo teste F. Os dados referentes à avaliação de fitotoxicidade do herbicida foram transformados para raiz quadrada de y +0,5. A comparação entre os tamanhos de sementes e o formato foi feita por meio do teste de Duncan a 5\% de significância, e entre doses do S-metolachlor, por análise de regressão nos níveis de $1 \%$ ou de $5 \%$ de significância.

Tabela 1 - Características físicas e químicas do solo utilizado. Capão do Leão-RS

\begin{tabular}{|c|c|c|c|c|c|c|c|}
\hline \multicolumn{8}{|c|}{ Análise granulométrica $\left(\right.$ dag kg $\left.^{-1}\right)$} \\
\hline \multicolumn{2}{|c|}{ Argila } & \multicolumn{2}{|c|}{ Silte } & \multicolumn{2}{|c|}{ Areia } & \multicolumn{2}{|c|}{ Densidade de partículas } \\
\hline \multicolumn{2}{|c|}{25,67} & \multicolumn{2}{|c|}{29,97} & \multicolumn{2}{|c|}{44,36} & \multicolumn{2}{|c|}{2,53} \\
\hline \multicolumn{8}{|c|}{ Análise química } \\
\hline \multirow{2}{*}{$\begin{array}{c}\mathrm{pH} \\
\left(\mathrm{H}_{2} \mathrm{O}\right) \\
\end{array}$} & $\mathrm{P}$ & $\mathrm{K}^{+}$ & $\mathrm{Na}$ & $\mathrm{Al}^{3+}$ & $\mathrm{Ca}^{2+}$ & $\mathrm{Mg}^{2+}$ & MO \\
\hline & \multicolumn{3}{|c|}{$\left(\mathrm{mg} \mathrm{dm}^{-3}\right)$} & \multicolumn{3}{|c|}{$\left(\mathrm{cmol}_{\mathrm{c}} \mathrm{dm}^{-3}\right)$} & $\left(\right.$ dag kg $\left.^{-1}\right)$ \\
\hline 4,4 & 1,3 & 46,0 & 10,0 & 1,6 & 1,9 & 1,0 & 2,18 \\
\hline
\end{tabular}




\section{RESULTADOS E DISCUSSÃO}

Não se observou nenhum tipo de interação entre os fatores tamanho de sementes, formato de sementes e doses do S-metolachlor em relação ao índice de velocidade de emergência. O tamanho das sementes de milho não influenciou o índice de velocidade de emergência das plântulas, cujas médias são apresentadas na Tabela 2. Todavia, plântulas provenientes de sementes chatas emergiram mais cedo em relação às oriundas de sementes de formato redondo (Tabela 2). Martinelli-Seneme et al. (2000) observaram que sementes de milho do cultivar AL-34 com formato chato apresentaram qualidade fisiológica superior à de formato redondo, por meio de vários testes de vigor, porém não constataram influência do tamanho na qualidade das sementes achatadas. Esses autores declaram que o tamanho das sementes é uma característica cujos efeitos vêm sendo estudados, considerando os mais diferentes componentes do desempenho tanto da semente como da planta dela resultante. Entretanto, Shieh \& McDonald (1982) afirmam que sementes redondas de milho apresentam maior incidência de danos, facilitando assim a infecção por patógenos, o que, conseqüentemente, reduz sua qualidade. Observou-se que o indice de velocidade de emergência das plântulas de milho não se alterou com a presença ou ausência do S-metolachlor no solo (Tabela 2), o que corrobora o resultado encontrado por Procópio et al. (2001), os quais observaram que o S-metolachlor não afetou a velocidade de emergência de plântulas de feijão. Resultados semelhantes também foram observados por Amaral \& Santos (1983) para os herbicidas butachlor, oxadiazon e pendimethalin, os quais não afetaram a velocidade de emergência de plântulas de vários cultivares de arroz.

Constatou-se interação entre os fatores tamanho e formato de sementes sobre a altura das plantas de milho, avaliada aos 7 e 14 dias após a emergência (DAE). As plantas provenientes de sementes chatas não diferiram em relação à altura de plantas aos 7 e 14 DAE, quando também provinham de sementes retidas nas peneiras 21,18 e 14 (Tabela 3 ). Isso demonstra que, quando as sementes

Tabela 2 - Médias do índice de velocidade de emergência (IVE) de plântulas de milho provenientes de três tamanhos e dois formatos de sementes após a aplicação de diferentes doses do S-metolachlor. Capão do Leão-RS, 2004

\begin{tabular}{|c|c|}
\hline Tamanho das sementes & IVE (dias) \\
\hline Peneira 21 & $5,66^{\mathrm{ns}}$ \\
\hline Peneira 18 & 5,66 \\
\hline Peneira 14 & 5,60 \\
\hline Formato das sementes & IVE (dias) \\
\hline Chata & $5,58 \mathrm{~b}$ \\
\hline Redonda & $5,70 \mathrm{a}$ \\
\hline Doses de S-metolachlor $\left(\mathrm{kg} \mathrm{ha}^{-1}\right)$ & IVE (dias) \\
\hline 0,00 & $5,63^{\mathrm{ns}}$ \\
\hline 0,48 & 5,56 \\
\hline 0,96 & 5,52 \\
\hline 1,44 & 5,74 \\
\hline 1,92 & 5,75 \\
\hline Média geral & 5,64 \\
\hline
\end{tabular}

* Médias de tratamentos não seguidas de mesma letra diferem a 5\% de probabilidade pelo teste $\mathrm{F}$.

Tabela 3 - Médias da altura de plantas aos 7, 14 e 21 dias após a emergência (DAE) de plantas de milho provenientes de três tamanhos e dois formatos de sementes. Capão do Leão-RS, 2004

\begin{tabular}{|c|c|c|c|c|c|}
\hline \multirow{4}{*}{$\begin{array}{c}\text { Tamanho } \\
\text { das sementes }\end{array}$} & \multicolumn{5}{|c|}{ Altura $(\mathrm{cm})$} \\
\hline & \multicolumn{2}{|c|}{$7 \mathrm{DAE}$} & \multicolumn{2}{|c|}{14 DAE } & $21 \mathrm{DAE}$ \\
\hline & \multicolumn{5}{|c|}{ Formato das sementes } \\
\hline & chata & redonda & chata & redonda & \\
\hline Peneira 21 & $10,01 \mathrm{Aa}$ & $10,71 \mathrm{Aa}$ & $21,55 \mathrm{Aa}$ & $23,73 \mathrm{Aa}$ & $28,15 \mathrm{a}$ \\
\hline Peneira 18 & $10,70 \mathrm{Aa}$ & 9,94Aab & $23,67 \mathrm{Aa}$ & $21,86 \mathrm{Aab}$ & $26,81 a$ \\
\hline Peneira 14 & $10,79 \mathrm{Aa}$ & $9,32 \mathrm{Bb}$ & $22,25 \mathrm{Aa}$ & $21,08 \mathrm{Ab}$ & $24,78 \mathrm{~b}$ \\
\hline $\mathrm{CV}(\%)$ & \multicolumn{2}{|c|}{16,70} & \multicolumn{2}{|c|}{15,54} & 15,17 \\
\hline
\end{tabular}

* Médias de tratamentos não seguidas de mesma letra minúscula na coluna e maiúscula na linha diferem a 5\% de probabilidade pelo teste de Duncan. 
tinham o formato chato, o tamanho delas não influenciou a altura inicial das plantas resultantes. Cazetta et al. (1995) verificaram que o tamanho das sementes de feijão mostra pouco efeito sobre a germinação e altura das plântulas. No entanto, quando as plantas eram originárias de sementes redondas e de menores dimensões (peneira 14), apresentavam menor altura aos 7 e $14 \mathrm{DAE}$, diferindo das plantas provenientes das sementes que ficaram retidas na peneira 21 (Tabela 3). Apenas na avaliação realizada aos 7 DAE detectou-se que as plantas oriundas de sementes retidas na peneira 14 apresentaram maior altura quando as sementes eram chatas. Aos 21 DAE observouse apenas efeito do tamanho das sementes sobre a altura das plantas de milho, sendo a altura das plantas originadas de sementes menores (peneira 14) menor em relação às plantas oriundas de sementes retidas nas peneiras 18 e 21 (Tabela 3). Esse fato demonstra que sementes maiores de um mesmo lote tendem a dar origem a plantas com maior crescimento inicial, fator importante na competição com as plantas daninhas na área pela interceptação de radiação solar. Ainda sobre as avaliações da altura de plantas, aos 7 e 21 DAE identificou-se interação entre os fatores formato de sementes e doses do $\mathrm{S}$-metolachlor. Nos tratamentos em que se aplicou 1,44 $\mathrm{g} \mathrm{ha}^{-1} \mathrm{de}$ S-metolachlor as plantas de milho tiveram menor crescimento quando resultavam de sementes redondas; nas demais doses do herbicida esse comportamento não

Tabela 4 - Médias da altura de plantas aos 7 e 21 dias após a emergência (DAE) de plantas de milho, provenientes de dois formatos de sementes, após a aplicação de cinco doses do herbicida S-metolachlor. Capão do Leão-RS, 2004

\begin{tabular}{|c|c|c|c|c|}
\hline \multirow{4}{*}{$\begin{array}{c}\text { Doses de } \\
\text { S-metolachlor } \\
\left(\mathrm{kg} \mathrm{ha}^{-1}\right)\end{array}$} & \multicolumn{4}{|c|}{ Altura $(\mathrm{cm})$} \\
\hline & \multicolumn{2}{|c|}{$7 \mathrm{DAE}$} & \multicolumn{2}{|c|}{$21 \mathrm{DAE}$} \\
\hline & \multicolumn{4}{|c|}{ Formato das sementes } \\
\hline & chata & redonda & chata & redonda \\
\hline 0,00 & $13,44 \mathrm{~A}$ & $13,73 \mathrm{~A}$ & $29,88 \mathrm{~A}$ & $32,81 \mathrm{~A}$ \\
\hline 0,48 & $13,18 \mathrm{~A}$ & $13,26 \mathrm{~A}$ & $30,21 \mathrm{~A}$ & $31,99 \mathrm{~A}$ \\
\hline 0,96 & $11,27 \mathrm{~A}$ & $10,10 \mathrm{~A}$ & $28,27 \mathrm{~A}$ & $28,63 \mathrm{~A}$ \\
\hline 1,44 & $10,10 \mathrm{~A}$ & $7,64 \mathrm{~B}$ & $27,25 \mathrm{~A}$ & $23,64 \mathrm{~B}$ \\
\hline 1,92 & $4,51 \mathrm{~A}$ & $5,21 \mathrm{~A}$ & $17,88 \mathrm{~A}$ & $15,26 \mathrm{~A}$ \\
\hline $\mathrm{CV}(\%)$ & \multicolumn{2}{|c|}{16,70} & \multicolumn{2}{|c|}{15,17} \\
\hline
\end{tabular}

* Médias de tratamentos não seguidas de mesma letra maiúscula na linha diferem a 5\% de probabilidade pelo teste de Duncan. foi observado (Tabela 4). O aumento nas doses do S-metolachlor provocou redução da altura das plantas de milho em todas as épocas avaliadas (Figura 1); na aplicação da maior dose do herbicida $\left(1,92 \mathrm{~g} \mathrm{ha}^{-1}\right)$, aproximadamente duas vezes a dose recomendada pelo fabricante para uso na cultura do milho, constatou-se redução de mais de 50\% na altura de plantas oriundas de sementes redondas (Tabela 4 e Figura 1). Na avaliação realizada
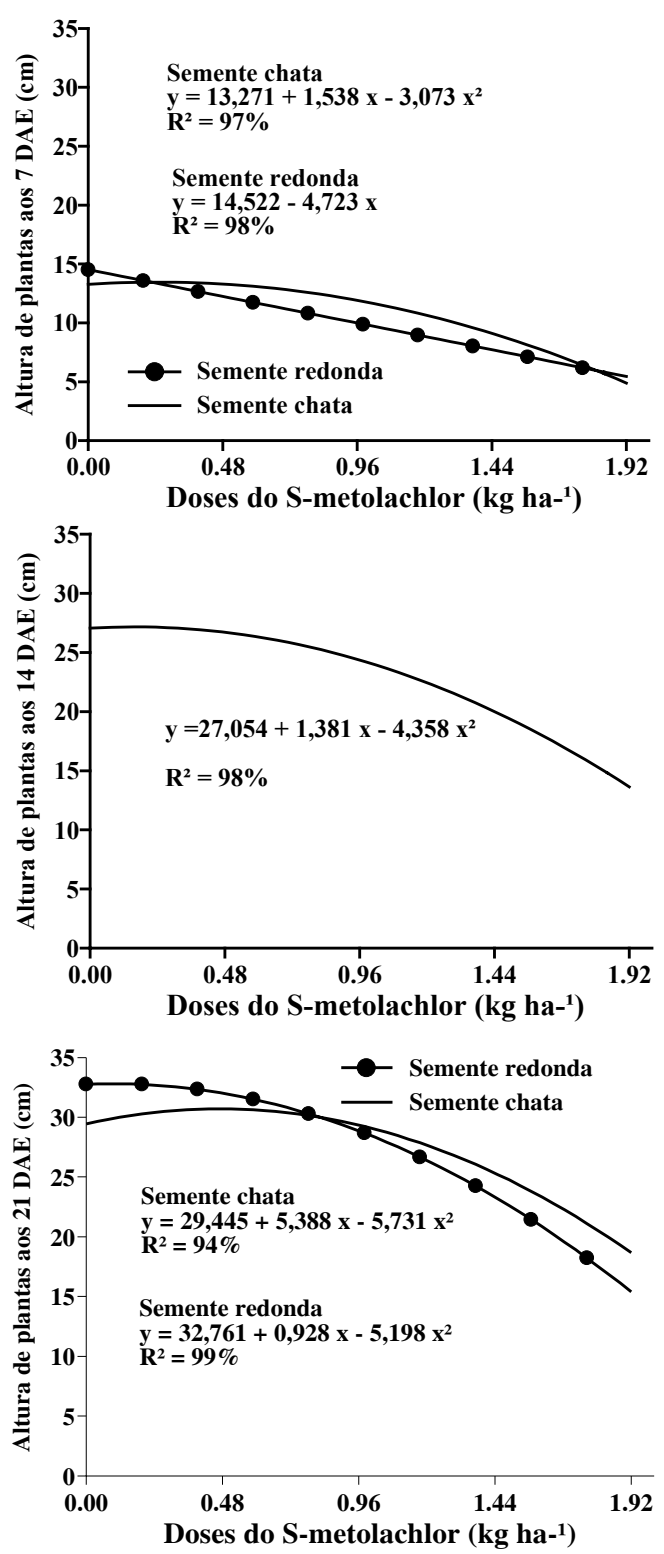

Figura 1 - Altura de plantas de milho aos 7, 14 e 21 dias após emergência (DAE), provenientes de sementes de dois formatos, após a aplicação de diferentes doses do herbicida S-metolachlor. Capão do Leão-RS. 
aos 14 DAE detectou-se apenas efeito das doses do herbicida sobre a altura de plantas de milho (Figura 1). Resultados do metolachlor afetando a altura de plantas foram observados por Rowe et al. (1990), os quais, trabalhando com 200 híbridos comerciais de milho, encontraram reduções na altura das plântulas tratadas variando de 26 a 73\%. Estes autores justificam tais resultados afirmando haver diferenças entre os híbridos quanto à quantidade absorvida e à habilidade de metabolização interna do herbicida.

Nas avaliações de fitotoxicidade resultante da aplicação do S-metolachlor, constatou-se interação entre os fatores tamanho e formato de sementes aos 7 e 21 DAE. Entre as plantas provenientes de sementes chatas não foram observadas variações no nível de fitotoxicidade nas avaliações realizadas aos 7 e 21 DAE, independentemente do tamanho dessas sementes (Tabela 5). Esse resultado também foi observado na avaliação realizada aos $21 \mathrm{DAE}$ para as plantas oriundas de sementes redondas; contudo, aos $7 \mathrm{DAE}$, menor fitotoxicidade do herbicida $(27,5 \%)$ foi verificada nas plantas que se originaram de sementes redondas que ficaram retidas na peneira 21 , ou seja, de maior tamanho. Na primeira e na última avaliação de fitotoxicidade (7 e 21 DAE), detectou-se que plantas vindas de sementes retidas na peneira 14 e que possuíam formato chato apresentaram menor grau de injúrias em relação à forma redonda (Tabela 5). Esses resultados indicam que o formato das sementes é fator importante na tolerância das plantas aos efeitos tóxicos do herbicida S-metolachlor, aplicado em pré-emergência, quando as sementes de milho são de menor tamanho. Na avaliação feita aos 14 DAE, o grau de toxicidade apresentado pelas espécies não foi influenciado pelo tamanho ou pelo formato das sementes que originaram as plantas de milho.

Interação entre os efeitos do formato das sementes e das doses do S-metolachlor foi observada na avaliação de fitotoxicidade realizada aos 14 DAE. Guando foi aplicado em pré-emergência $1,44 \mathrm{~g} \mathrm{ha}^{-1}$ de S-metolachlor, constatou-se, aos $14 \mathrm{DAE}$, que as plantas oriundas de sementes chatas apresentaram menor fitotoxicidade em comparação às provenientes de sementes redondas: 6,75 e $32,08 \%$, respectivamente (Tabela 6). O incremento das doses do herbicida ocasionou aumento da toxicidade às plantas de milho,

Tabela 6 - Médias de fitotoxicidade aos 14 dias após a emergência em plantas de milho provenientes de dois formatos de sementes, após a aplicação de cinco doses do herbicida S-metolachlor. Capão do Leão-RS, 2004

\begin{tabular}{|c|c|c|}
\hline \multirow{2}{*}{$\begin{array}{c}\text { Doses de S-metolachlor } \\
\left(\mathrm{kg} \mathrm{ha}^{-1}\right)\end{array}$} & \multicolumn{2}{|c|}{ Fitotoxicidade 14 DAE (\%) } \\
\cline { 2 - 3 } & \multicolumn{2}{|c|}{ Formato das sementes } \\
\cline { 2 - 3 } & chata & redonda \\
\hline 0,00 & $0,00 \mathrm{~A}$ & $0,00 \mathrm{~A}$ \\
\hline 0,48 & $0,63 \mathrm{~A}$ & $1,02 \mathrm{~A}$ \\
\hline 0,96 & $6,46 \mathrm{~A}$ & $12,29 \mathrm{~A}$ \\
\hline 1,44 & $6,75 \mathrm{~B}$ & $32,08 \mathrm{~A}$ \\
\hline 1,92 & $59,17 \mathrm{~A}$ & $55,97 \mathrm{~A}$ \\
\hline $\mathrm{CV}(\%)$ & \multicolumn{3}{|c|}{44,14} \\
\hline
\end{tabular}

* Médias de tratamentos não seguidas de mesma letra maiúscula na linha diferem a 5\% de probabilidade pelo teste de Duncan.

Tabela 5 - Médias de fitotoxicidade aos 7, 14 e 21 dias após a emergência (DAE) em plantas de milho provenientes de três tamanhos e dois formatos de sementes. Capão do Leão-RS, 2004

\begin{tabular}{|c|c|c|c|c|c|}
\hline \multirow{4}{*}{$\begin{array}{c}\text { Tamanho das } \\
\text { sementes }\end{array}$} & \multicolumn{5}{|c|}{ Fitotoxicidade (\%) } \\
\hline & \multicolumn{2}{|c|}{7 DAE } & $14 \mathrm{DAE}$ & \multicolumn{2}{|c|}{$21 \mathrm{DAE}$} \\
\hline & \multicolumn{2}{|c|}{ Formato das sementes } & & \multicolumn{2}{|c|}{ Formato das sementes } \\
\hline & chata & redonda & & chata & redonda \\
\hline Peneira 21 & $29,95 \mathrm{Aa}$ & $27,50 \mathrm{Ab}$ & $15,75^{\mathrm{ns}}$ & $15,00 \mathrm{Aa}$ & $9,58 \mathrm{Aa}$ \\
\hline Peneira 18 & $30,50 \mathrm{Aa}$ & $37,25 \mathrm{Aa}$ & 18,68 & $9,13 \mathrm{Aa}$ & $17,33 \mathrm{Aa}$ \\
\hline Peneira 14 & $25,00 \mathrm{Ba}$ & $38,00 \mathrm{Aa}$ & 17,88 & $8,25 \mathrm{Ba}$ & $18,00 \mathrm{Aa}$ \\
\hline $\mathrm{CV}(\%)$ & \multicolumn{2}{|c|}{23,97} & 44,14 & \multicolumn{2}{|c|}{61,16} \\
\hline
\end{tabular}

* Médias de tratamentos não seguidas de mesma letra minúscula na coluna e maiúscula na linha diferem a 5\% de probabilidade pelo teste de Duncan. 
independentemente das características das sementes que as originaram (Figura 2). A elevação dos sintomas de fitotoxicidade, avaliada aos 14 DAE, iniciou-se com a aplicação de doses menores do herbicida nas plantas oriundas de sementes redondas (Figura 2). A aplicação da maior dose do S-metolachlor (1,44 $\left.\mathrm{g} \mathrm{ha}^{-1}\right)$ acarretou, como média geral, cerca
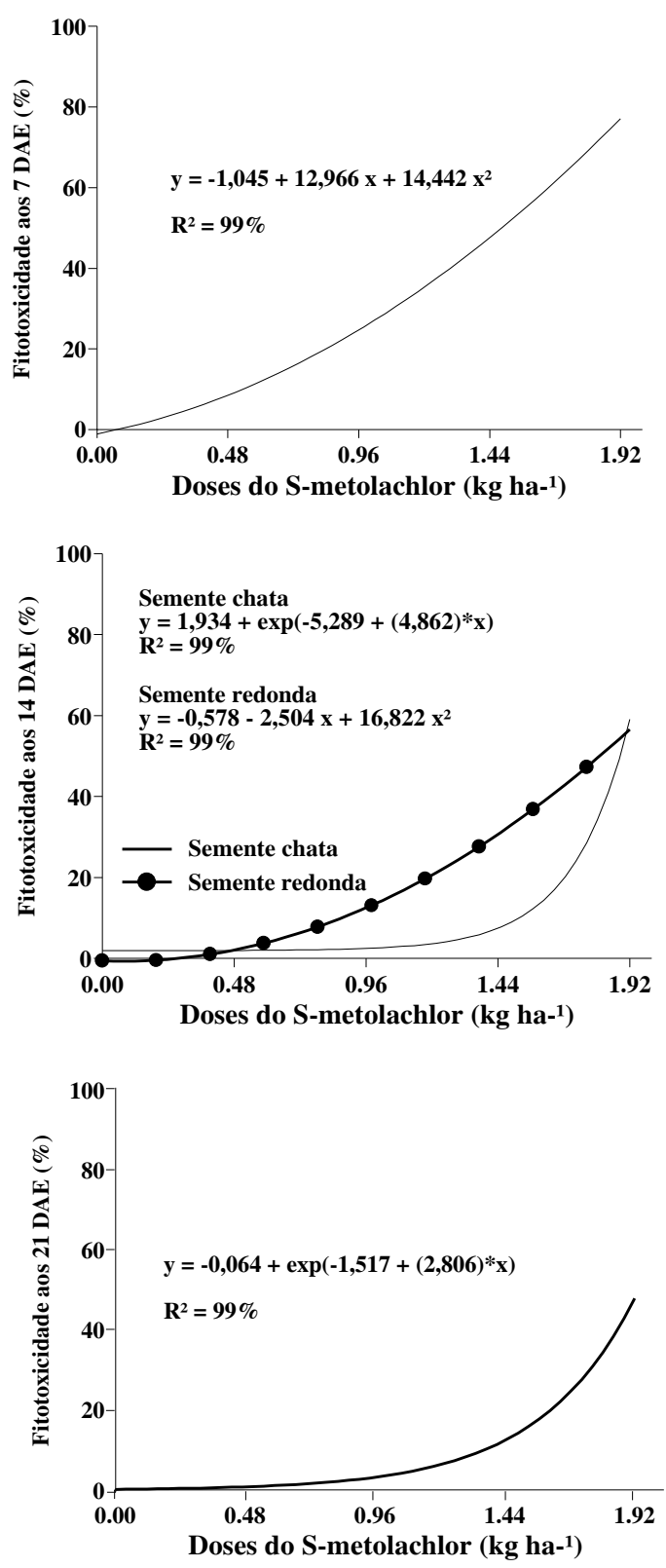

Figura 2 - Toxicidade em plantas de milho aos 7, 14 e 21 dias após a emergência (DAE), decorrente da aplicação de diferentes doses do herbicida S-metolachlor. Capão do Leão-RS. de 50\% de toxicidade às plantas de milho aos 21 DAE, o que representa um grau relativamente elevado. Esse fato demonstra que a seletividade desse herbicida à cultura do milho é altamente dependente da dose aplicada. Em decorrência disso, cuidados visando a nãoocorrência de sobreposição da faixa de aplicação do S-metolachlor são necessários, a fim de garantir níveis de injúrias que não resultem em redução na produtividade da cultura.

O acúmulo de biomassa seca da parte aérea e das raízes das plantas de milho, coletada aos 21 DAE, teve influência tanto do tamanho como do formato das sementes que as originaram. Pela análise da Tabela 7 , constata-se que plantas que provinham de sementes chatas apresentaram menor biomassa seca, tanto da parte aérea como das raízes, quando essas sementes também possuíam menores dimensões (peneira 14), porém entre as peneiras 18 e 21 não se detectaram diferenças significativas. A biomassa seca da parte aérea e das raízes formada pelas plantas de milho oriundas de sementes redondas era menor quando as sementes também apresentavam menor tamanho; entretanto, em relação às raízes, não se detectaram diferenças entre plantas provenientes das peneiras $14 \mathrm{e}$ 18 (Tabela 7). As plantas que foram originadas de sementes retidas na peneira 21 e com formato redondo acumularam maior biomassa seca da parte aérea e das raízes. Esses resultados estão de acordo com os encontrados por Nachi \& Le Guen (1996), os quais observaram correlação positiva entre o tamanho das sementes de genótipos de Vicia faba e o acúmulo de biomassa seca pelas plantas.

O aumento das doses aplicadas do Smetolachlor ocasionou reduções na aquisição de biomassa seca tanto da parte aérea como das raízes de plantas de milho, porém maior decréscimo se observou quanto ao acúmulo de biomassa seca das raízes (Figura 3). Silva et al. (1981) observaram inibição de 50\% do crescimento $\left(\mathrm{I}_{50}\right)$ das plantas de soja com a aplicação correspondente a 600, 1.050 e $1.150 \mathrm{~g} \mathrm{ha}^{-1}$ de metribuzin, para as plantas oriundas das sementes retidas nas peneiras 10, 13 e 15, respectivamente. Esses autores argumentam que sementes dos tamanhos 13 e 15 podem dar origem a plantas com maior reserva para metabolização do produto. 
Tabela 7 - Médias da biomassa seca da parte aérea e das raízes aos 21 dias após a emergência de plantas de milho provenientes de três tamanhos e dois formatos de sementes. Capão do Leão-RS, 2004

\begin{tabular}{|c|c|c|c|c|}
\hline \multirow{4}{*}{$\begin{array}{l}\text { Tamanho das } \\
\text { sementes }\end{array}$} & \multicolumn{4}{|c|}{ Biomassa seca (g) } \\
\hline & \multicolumn{2}{|c|}{ Parte aérea } & \multicolumn{2}{|c|}{ Raízes } \\
\hline & \multicolumn{4}{|c|}{ Formato das sementes } \\
\hline & chata & redonda & chata & redonda \\
\hline Peneira 21 & $1,10 \mathrm{Ba}$ & $1,40 \mathrm{Aa}$ & $1,69 \mathrm{Ba}$ & $2,06 \mathrm{Aa}$ \\
\hline Peneira 18 & $1,10 \mathrm{Aa}$ & $1,19 \mathrm{Ab}$ & $1,64 \mathrm{Aa}$ & $1,57 \mathrm{Ab}$ \\
\hline Peneira 14 & $0,91 \mathrm{Ab}$ & $0,92 \mathrm{Ac}$ & $1,31 \mathrm{Ab}$ & $1,36 \mathrm{Ab}$ \\
\hline CV (\%) & \multicolumn{2}{|c|}{18,57} & \multicolumn{2}{|c|}{24,37} \\
\hline
\end{tabular}

* Médias de tratamentos não seguidas de mesma letra minúscula na coluna e maiúscula na linha diferem a $5 \%$ de probabilidade pelo teste de Duncan.
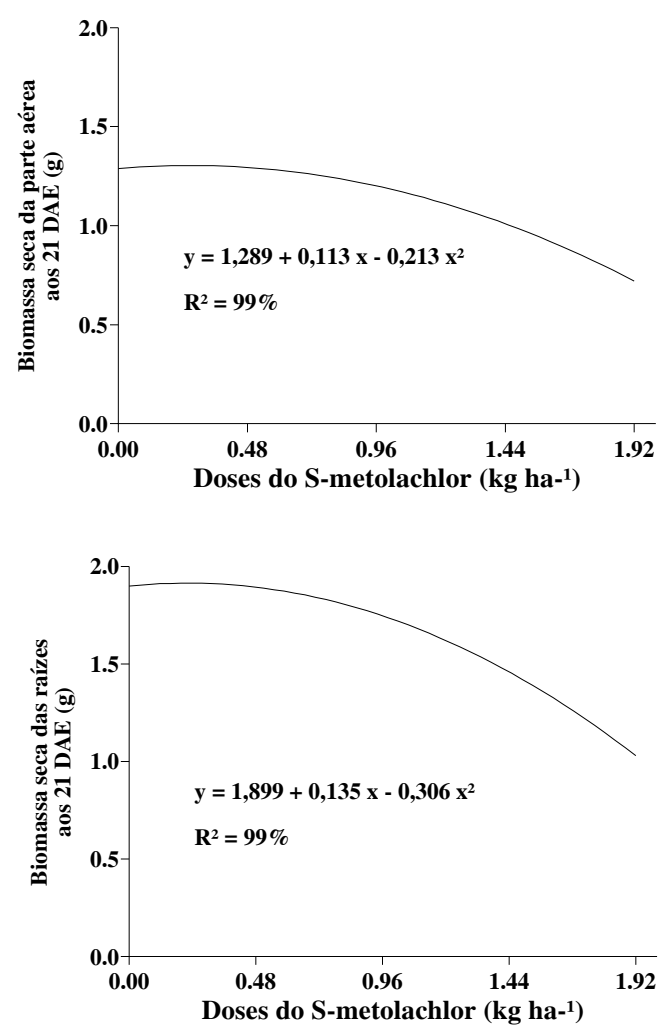

Figura 3 - Biomassa seca da parte aérea e das raízes de plantas de milho aos 21 dias após a emergência (DAE), após a aplicação de diferentes doses do herbicida S-metolachlor. Capão do Leão-RS.

De acordo com os resultados, pode-se concluir que o formato das sementes é um fator importante na tolerância das plantas de milho aos efeitos tóxicos do herbicida
S-metolachlor, aplicado em pré-emergência, quando as sementes são de menor tamanho. A maior fitotoxicidade promovida pelo herbicida S-metolachlor foi observada em plantas provenientes de sementes redondas. $\mathrm{O}$ aumento das doses do herbicida S-metolachlor ocasionou reduções na aquisição de biomassa seca tanto da parte aérea como das raízes de plantas de milho, porém maior decréscimo se observou quanto ao acúmulo de biomassa seca das raízes.

\section{LITERATURA CITADA}

AMARAL, A. S.; SANTOS, E. C. Efeitos de herbicidas na emergência de plântulas de arroz. R. Bras. Sementes, v. 5, p. 37-45, 1983.

ANDERSEN, R. N. Influence of soybean seed size on response to atrazine. Weed Sci., v. 18, p. 162-164, 1970.

BOLDT, L. D.; BARRETT, M. Factors in alachlor and metolachlor injury to corn (Zea mays) seedlings. Weed Technol., v. 3, p. 303-306, 1989.

BREAUX, E. J. Initial metabolism of acetochlor in tolerant and susceptible seedlings. Weed Sci., v. 35, p. 463-467, 1987.

CARGILL, R. L.; SANTELMANN, P. W. Influence of peanut seed and quality and variety on susceptibility to herbicides. Agron. J., v. 63, p. 98-100, 1971.

CAZETTA, J. O.; SADER, R.; IKEDA, M. Efeito do tamanho no desempenho germinativo de sementes de feijoeiro (Phaseolus vulgaris L.). Ci. Jaboticabal, v. 23, p. 65-71, 1995.

COTTINGHAM, C. K.; HATZIOS, K. K. Basis of differential tolerance of two corn hybrids (Zea mays) to metolachlor. Weed Sci., v. 40, p. 359-363, 1992.

DIXON, G. A.; STOLLER, E. W. Differential toxicity, absorption, translocation, and metabolism of metolachlor in corn (Zea mays) and yellow nutsedge (Cyperus esculentus). Weed Sci., v. 30, p. 225-230, 1982.

FUERST, E. P.; GRONWALD, J. W. Induction of rapid metabolism of metolachlor in sorghum shooys by CGA92194 and other antidotes. Weed Sci., v. 34, p. 354-361, 1986.

JORDAN, G. L.; HARVEY, R. G. Response of processing peas (Pisum sativum) and annual weeds to acetanilide herbicides. Weed Sci., v. 26, p. 313-317, 1978. 
KUNKEL, D. L.; BELLINDER, R. R.; STEFFENS, J. C. Safeners reduce corn (Zea mays) chloroacetanilide and dicamba injury under different soil temperatures. Weed Technol., v. 10, p. 115-120, 1996.

MAGUIRE, J. D. Speeds germination-aid selection and evolution for seedling emergence and vigor. Crop. Sci., v. 2, p. 176-177, 1962.

MARTINELLI-SENEME, A.; ZANOTTO, M. D.;

NAKAGAWA, J. Efeitos da forma e do tamanho na qualidade de sementes de milho, cultivar AL-34. R. Bras. Sementes, v. 22, p. 232-238, 2000.

NACHI, N.; LE GUEN, J. Dry matter accumulation and seed yield in faba bean (Vicia Faba L.) genotypes. Agronomie, v. 16 , p. 47-53, 1996.

PROCOPIO, S. O. et al. Efeito do tamanho de sementes sobre a tolerância do feijoeiro ao S-metolachlor, em condições de baixa temperatura. R. Bras. Herb., v. 2, p. 133-141, 2001.
RIBEIRO JUNIOR, J. I. Análises estatísticas no SAEG. Viçosa, MG: Universidade Federal de Viçosa, 2001. $301 \mathrm{p}$.

ROWE, L.; ROSSMAN, E.; PENNER, D. Differential response of corn hybrids and inbreds to metolachlor. Weed Sci., v. 38, p. 563-566, 1990.

SHIEH, W. J.; McDONALD, M. B. The influence of seed size, shape and treatment on imbred seed corn quality. Seed Sci. Tecnol., v. 10, p. 307-13, 1982.

SILVA J. F. et al. Tolerância do tamanho da semente de soja [Glycine max (L.) Merr. ] ao metribuzin. Planta Daninha, v. 4, p. 92-96, 1981.

VIGER, P. R.; EBERLEIN, C. V.; FUERST, E. P. Influence of available soil water content, temperature, and CGA154281 on metolachlor injury to corn. Weed Sci., v. 39, p. 227-231, 1991. 